Supporting Information for

\title{
Facile Mechanochemical Synthesis of Malleable Biomass-Derived Network Polyurethanes and Their Shape-Memory Applications
}

Hyunwoo Kim, ${ }^{a, \dagger}$ Inhwan Cha,,${ }^{a}{ }^{\dagger}$ Youngsum Yoon, ${ }^{a}$ Byeong Jun Cha, ${ }^{a}$ Jiwon Yang, ${ }^{a}$ Young Dok Kim, ${ }^{a}$ and Changsik Song, ${ }^{a, *}$

aDepartment of Chemistry, Sungkyunkwan University, 2066 Seobu-ro, Jangan-gu, Suwon, Gyeonggi 16419, Republic of Korea

*E-mail: songcs@skku.edu

$\uparrow$ These authors contributed equally to this work.

Number of pages: 25

Number of figures: 19

Number of tables: 1 


\section{Contents}

\section{General Procedure of model compounds}

$\checkmark \quad$ Fig. S1 FTIR spectra of NPU50-1 and starting materials S4

$\checkmark \quad$ Fig. S2 Isothermal TGA of NPUs S5

$\checkmark \quad$ Fig. S3 Stability of furan using model compound S6

$\checkmark \quad$ Fig. S4 high-temperature swelling experiments of NPU50-1 S7

$\checkmark \quad$ Fig. S5-8 TGA, TMA, Tan $\delta$ and DSC curves of NPUs S8

$\checkmark \quad$ Fig. S9 Storage modulus and tan $\delta$ curves of NPU50s using DMTA.

$\checkmark \quad$ Fig. S10 Isothermal stress-relaxation analysis of NPUs

$\checkmark \quad$ Fig. S11 Strain sweep analysis of NPU50-1.

$\checkmark \quad$ Fig. S12 Arrhenius plots of NPUs' viscosity behavior S16

$\checkmark \quad$ Fig. S13 VT-FTIR spectra of NPU50-1 from $30{ }^{\circ} \mathrm{C}$ to $200{ }^{\circ} \mathrm{C}$

$\checkmark \quad$ Fig. S14 Calculation of the urethane-DBTDL binding constant using ${ }^{1} \mathrm{H}-\mathrm{NMR}$ S18

$\checkmark \quad$ Urethane and Tin catalyst binding test and analysis S19

$\checkmark \quad$ Table S1 Calculation of Urethane-DBTDL constants

$\checkmark \quad$ Fig. S15-17 DMTA, Normalized E' and SS curves of the original and reprocessed NPU50-1 ...S21

$\checkmark \quad$ Fig. S18 ${ }^{1} \mathrm{H}$-NMR of furfuryl $N$-propylcarbamate S24

$\checkmark \quad$ Fig. S19 ${ }^{1} \mathrm{H}$-NMR of furfuryl $N$-hexylcarbamate $\mathrm{S} 24$

$\checkmark \quad$ References S25 


\section{General Procedure for the synthesis of model compounds}

A corresponding alcohol (A, C: furfuryl alcohol; B, D: benzyl alcohol; $3.0 \mathrm{mmol}$ ) was dissolved in $3 \mathrm{~mL}$ of anhydrous tetrahydrofuran under an inert atmosphere at room temperature. Then, alkyl isocyanate (A, D: propyl isocyanate; B, C: hexyl isocyanate; $3.0 \mathrm{mmol}$ ) and DBTDL (2.5 mol\%) were added sequentially. the reaction mixture was stirred for overnight in room temperature. After reaction, the mixture was extracted with water/ethyl acetate. The organic layer was dried over $\mathrm{Na}_{2} \mathrm{SO}_{4}$, filtered, and evaporated under vacuum. The residue was subjected to flash column chromatography and to obtain the model compounds A D.

Furfuryl N-propylcarbamate (A). Yield: $77 \%$ as a yellowish oil; ${ }^{1} \mathrm{H}-\mathrm{NMR}(500 \mathrm{MHz}$, $\left.\mathrm{CDCl}_{3}\right) \delta: 7.42(\mathrm{dd}, 1 \mathrm{H}), 6.40(\mathrm{~m}, 1 \mathrm{H}), 6.36(\mathrm{~m}, 1 \mathrm{H}), 5.05(\mathrm{~s}, 2 \mathrm{H}), 4.71$ (brs, $\left.1 \mathrm{H}\right), 3.13-3.17$ (brs, 2H), 1.49-1.54 (m, 2H), $0.91(\mathrm{t}, 3 \mathrm{H})$.

Benzyl N-hexylcarbamate (B). Yield: $84 \%$ as a clear oil; ${ }^{1} \mathrm{H}-\mathrm{NMR}\left(500 \mathrm{MHz}, \mathrm{CDCl}_{3}\right) \delta$ : 7.29-7.38 (m, 5H), 5.10(s, 2H), 4.71 (brs, 1H), 3.19 (q, 2H), 1.49-1.54 (m, 2H), 1,26-1.33 (m, 6H) $0.88(\mathrm{t}, 3 \mathrm{H})$.

Furfuryl $N$-hexylcarbamate (C). Yield: $82 \%$ as a yellowish oil; ${ }^{1} \mathrm{H}-\mathrm{NMR}(500 \mathrm{MHz}$, $\left.\mathrm{CDCl}_{3}\right) \delta: 7.42(\mathrm{dd}, 1 \mathrm{H}), 6.40(\mathrm{~m}, 1 \mathrm{H}), 6.36(\mathrm{~m}, 1 \mathrm{H}), 5.05(\mathrm{~s}, 2 \mathrm{H}), 4.70(\mathrm{brs}, 1 \mathrm{H}), 3.17(\mathrm{q}, 2 \mathrm{H})$, 1.49-1.54 (m, 2H), 1,26-1.33 (m, 6H) $0.88(\mathrm{t}, 3 \mathrm{H})$.

Benzyl N-propylcarbamate (D). Yield: $79 \%$ as a clear oil; ${ }^{1} \mathrm{H}-\mathrm{NMR}\left(500 \mathrm{MHz}, \mathrm{CDCl}_{3}\right) \delta$ : 7.31-7.36 (m, 5H), 5.09 (s, 2H), 4.78 (brs, 1H), 3.10-3.20 (m, 2H), 1.45-1.56 (m, 2H) 0.91 (t, $3 \mathrm{H})$. 


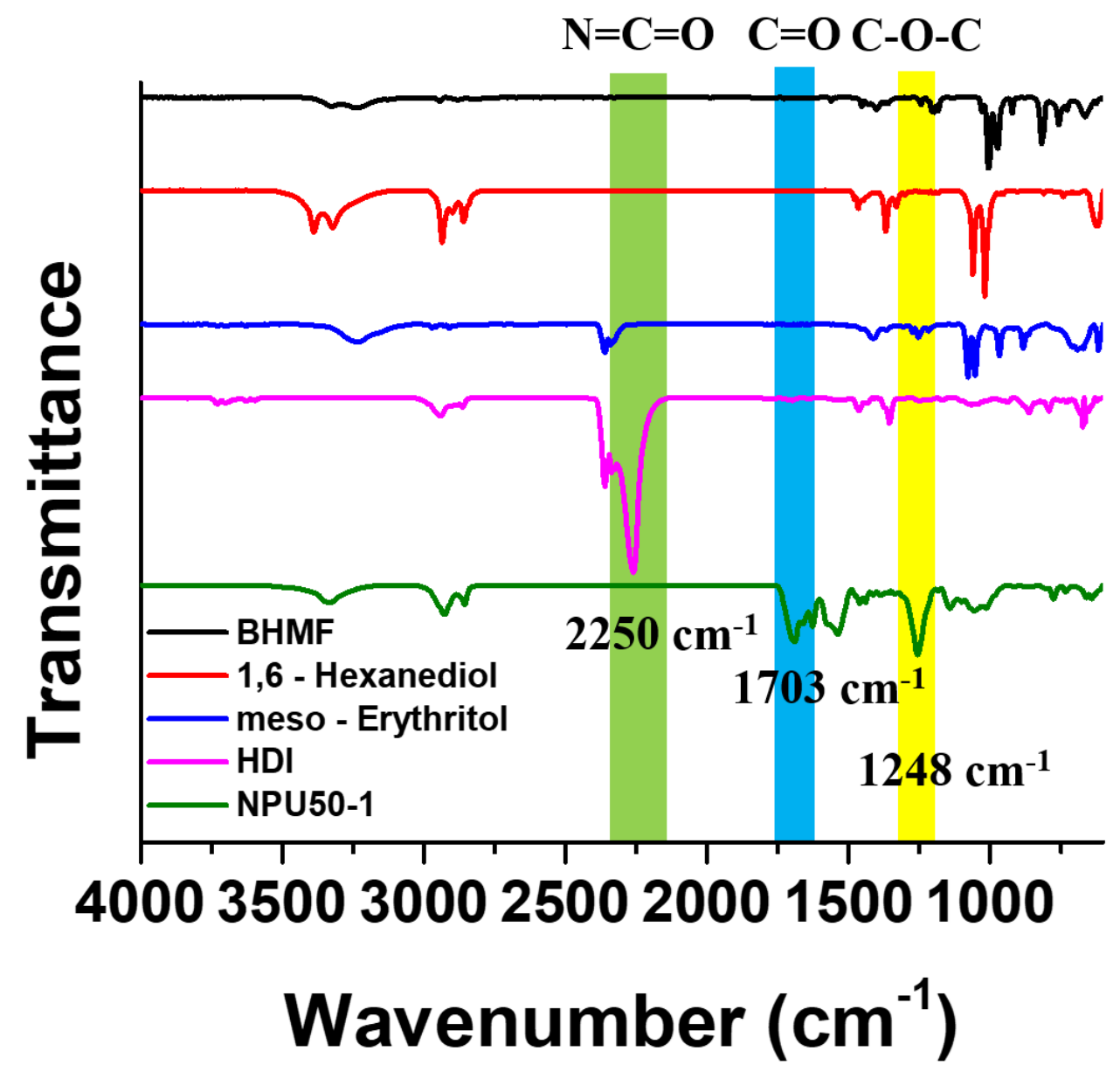

Fig. S1 FTIR spectra of NPU50-1 and its starting materials. 


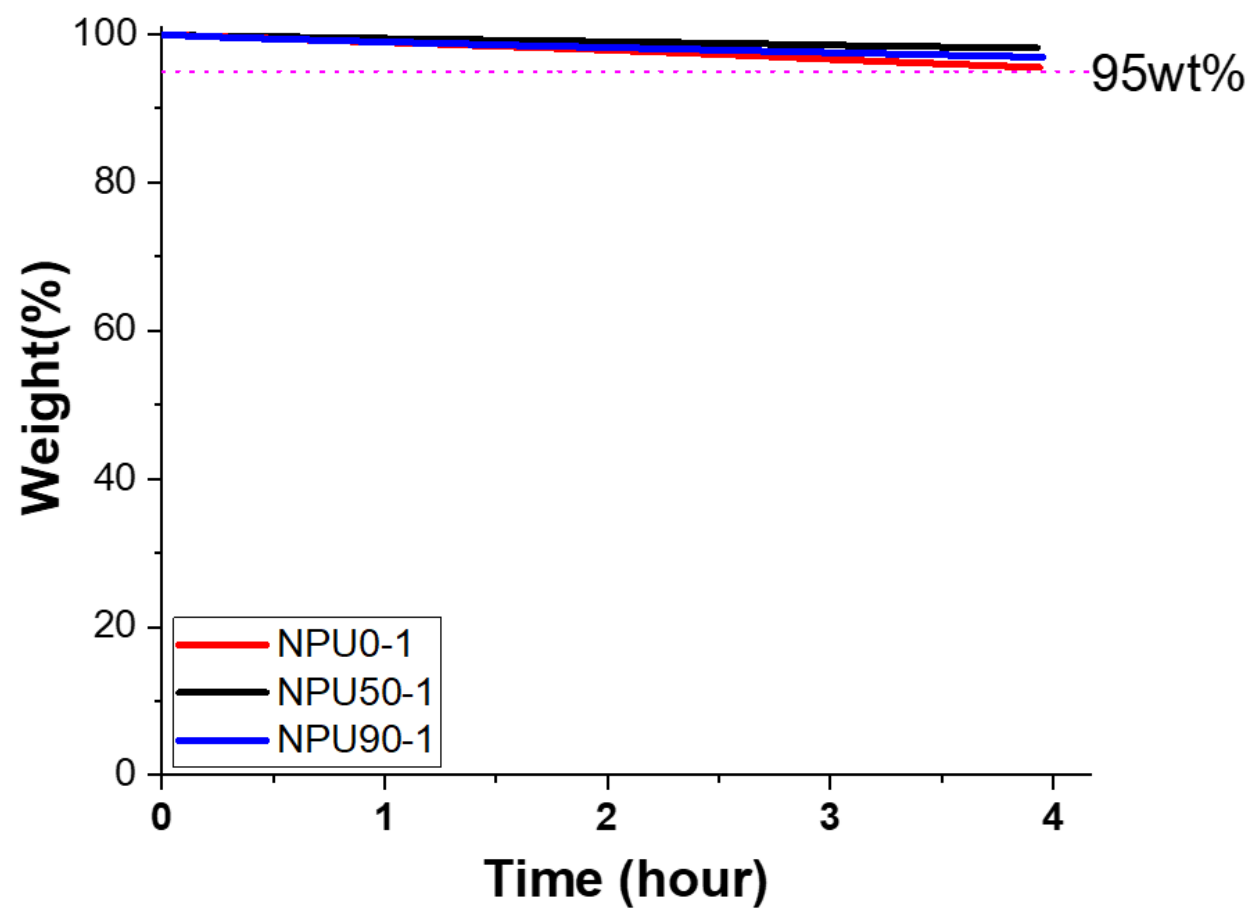

Fig. S2 Isothermal TGA curves of NPU0-1 (red), NPU50-1 (black), and NPU90-1 (blue) at $160{ }^{\circ} \mathrm{C}$ for $4 \mathrm{~h}$. 


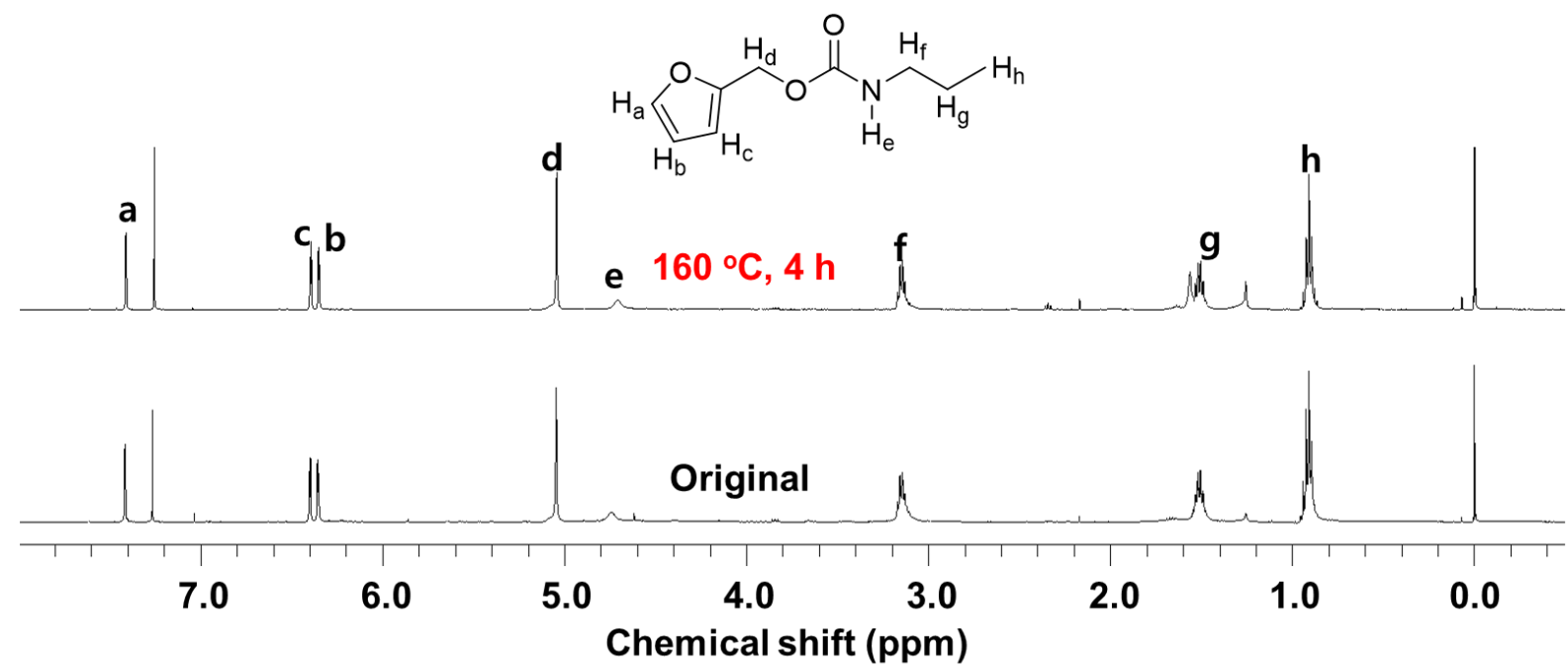

Fig. S3 ${ }^{1} \mathrm{H}$-NMR spectra of furfuryl $N$-propylcarbamate before and after thermal treatment at $160{ }^{\circ} \mathrm{C}$ for 4 hours. 


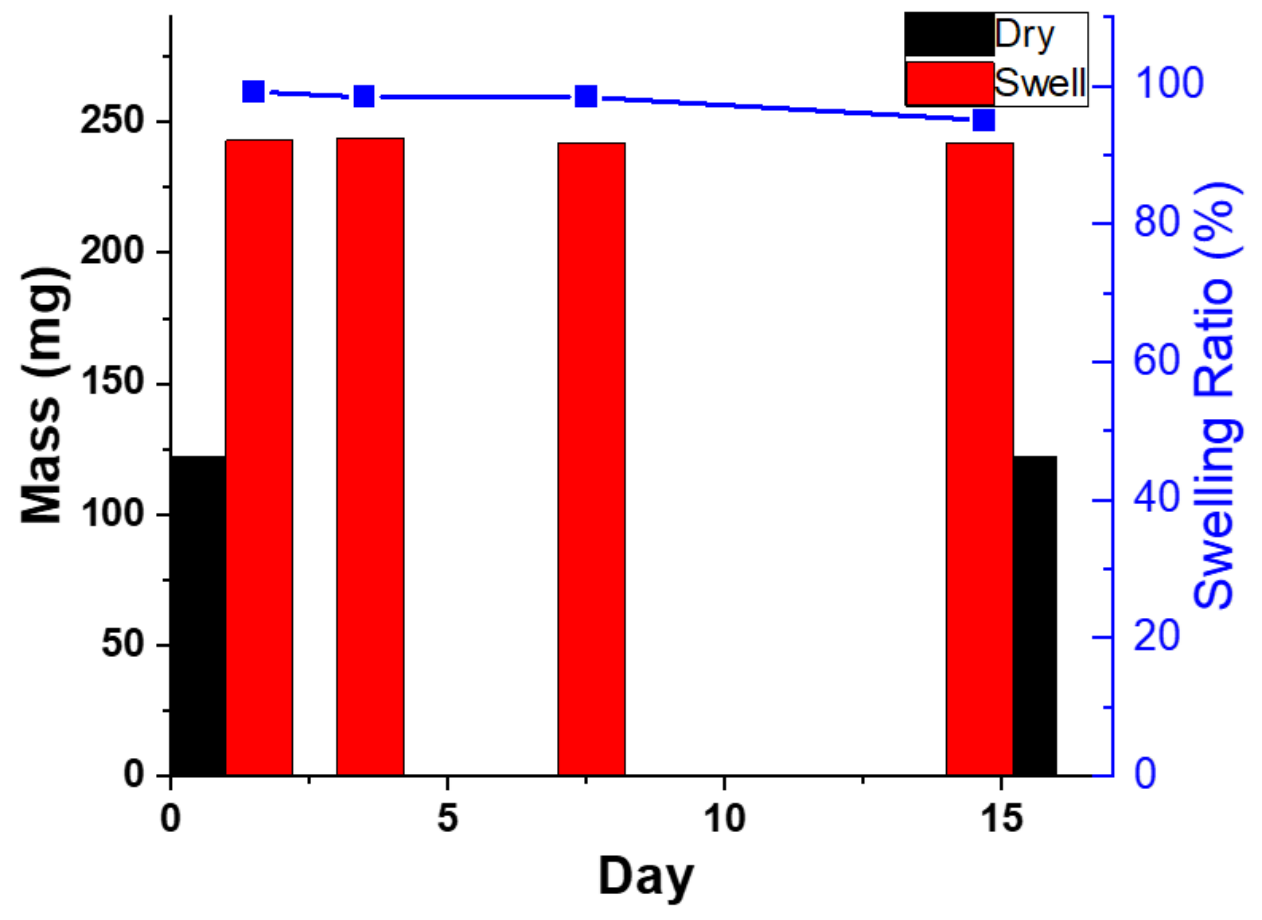

Fig. S4 The dry (black bar) and solvent-uptaken (red bar) masses and the swelling ratio (blue dot) of NPU50-1 immersed in DMF over 14 days at $90{ }^{\circ} \mathrm{C}\left(>\mathrm{T}_{\mathrm{g}}\right)$. 


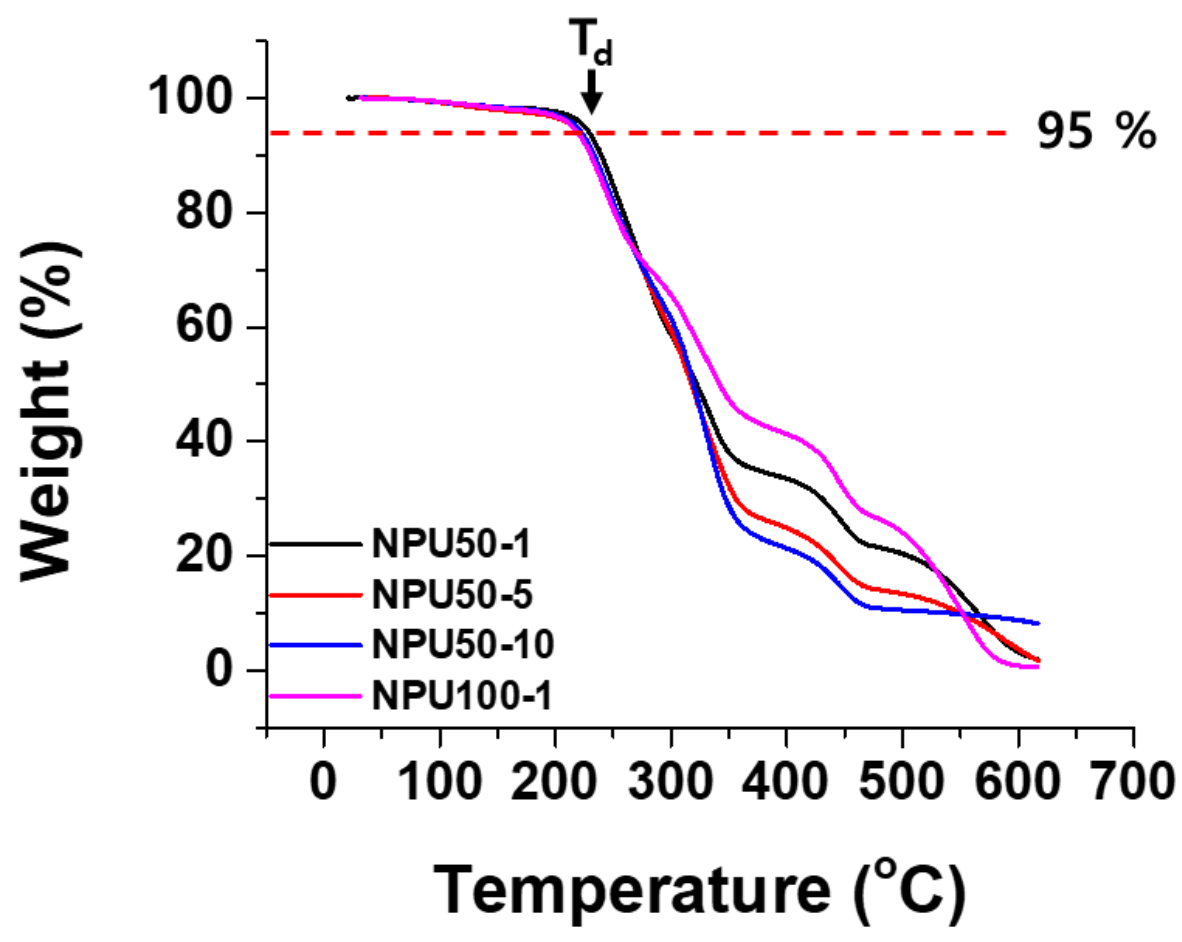

Fig. S5 TGA curves of NPU50-1 (black), NPU50-5 (red), NPU50-10 (blue) and NPU100-1 (purple). The decomposition temperature $\left(\mathrm{T}_{\mathrm{d}}\right)$ was determined by the $5 \%$ weight loss from the original weight. 


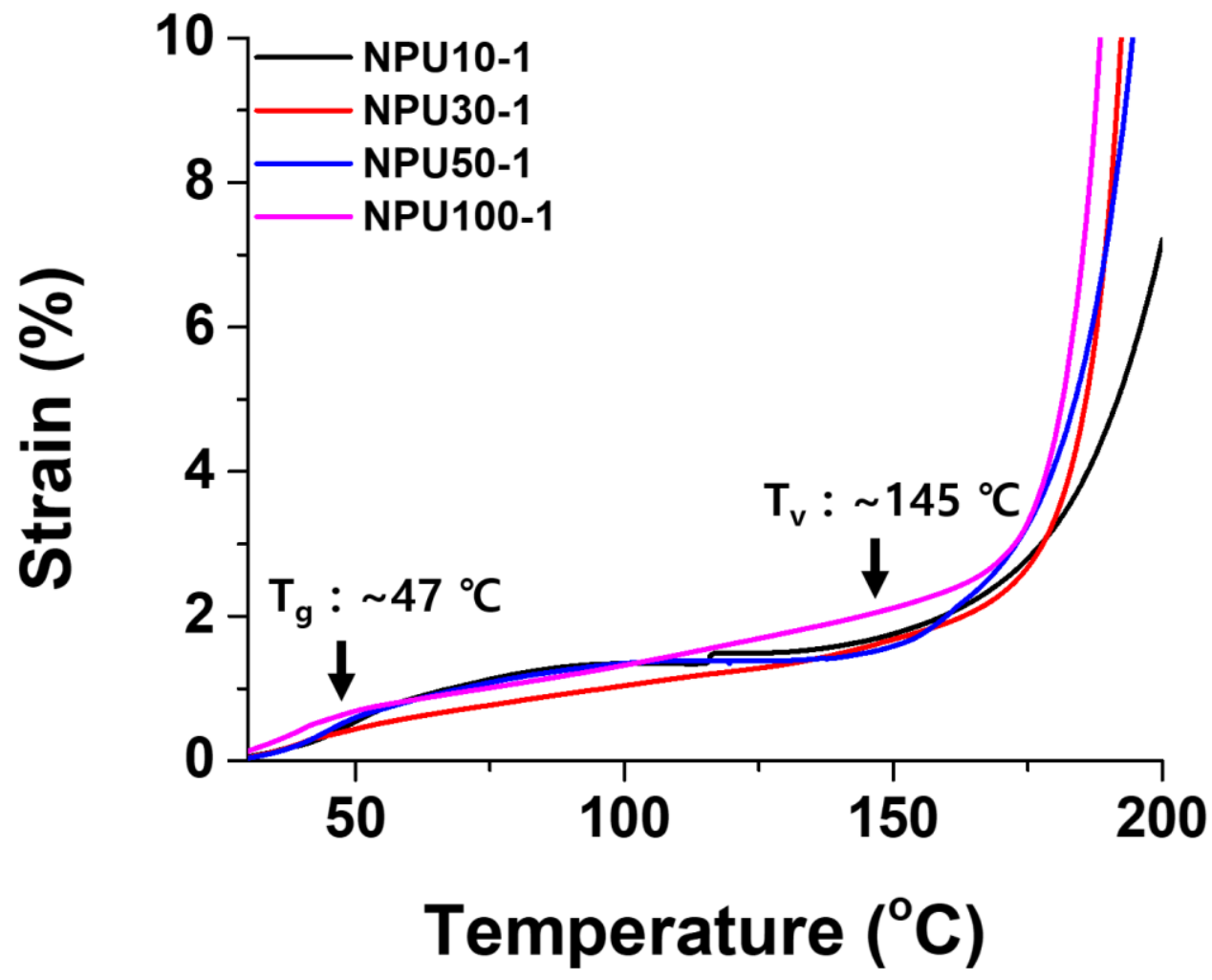

Fig. S6 TMA curves of NPU10-1 (black), NPU30-1 (red), NPU50-1 (blue) and NPU100-1 (purple). 


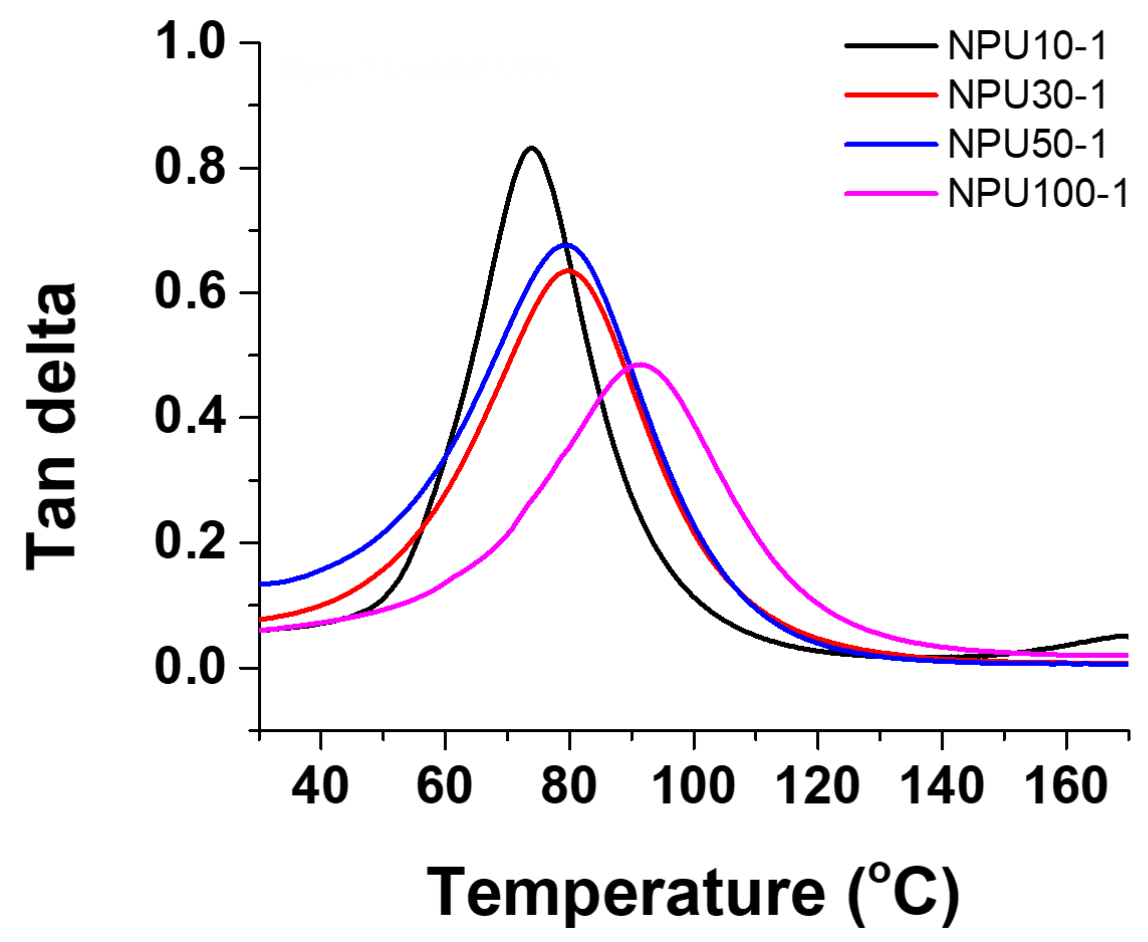

Fig. S7 Tan $\delta$ curves of NPU10-1 (black), NPU30-1 (red), NPU50-1 (blue) and NPU100-1 (purple) using DMTA. The molar content of BHMF in the diol (BHMF $+1,6$-hexanediol) are $0.1,0.3,0.5$, and 1 , respectively. 


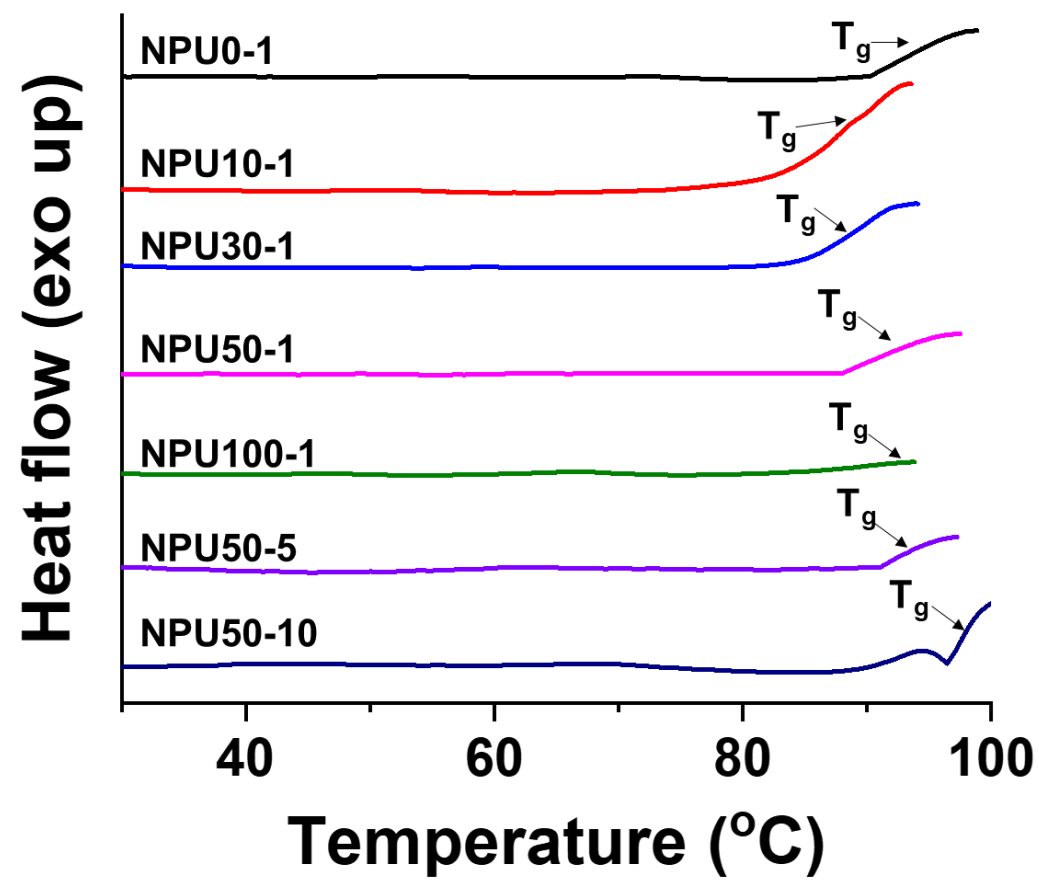

Fig. S8 DSC curves (the first cooling) of NPUs. $T_{\mathrm{g}}$ S were obtained from the points with arrows. 


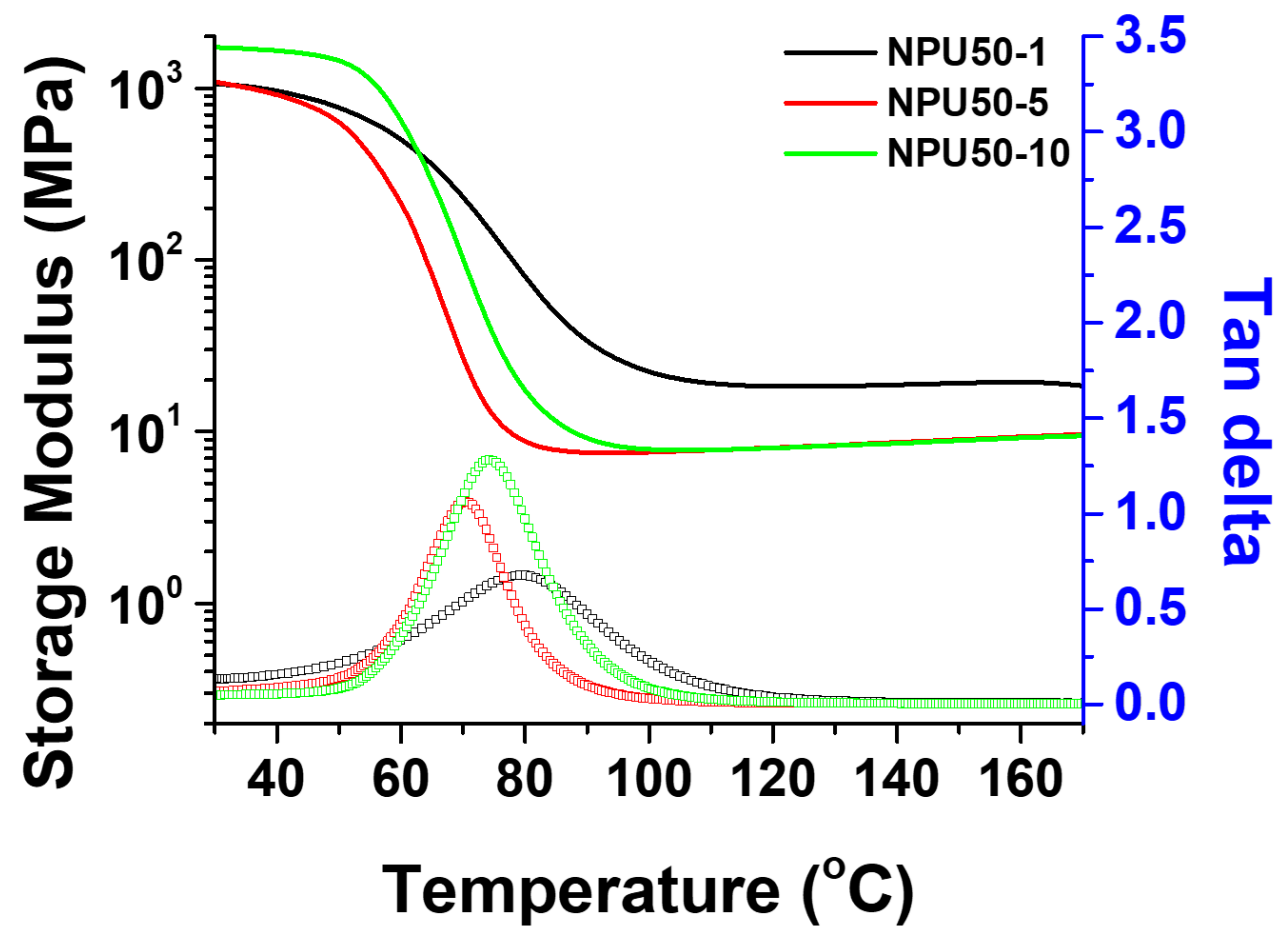

Fig. S9 Storage modulus (solid lines) and $\tan \delta$ (empty square) curves of NPU50-1 (black), NPU50-5 (red) and NPU50-10 (green) using DMTA. The catalyst (DBTDL) loadings are 1, 5, and $10 \mathrm{~mol} \%$, respectively. 
(a)

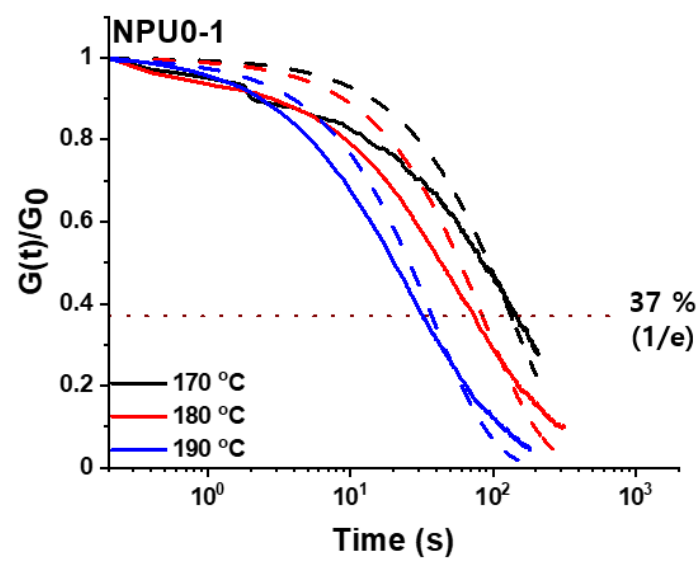

(c)

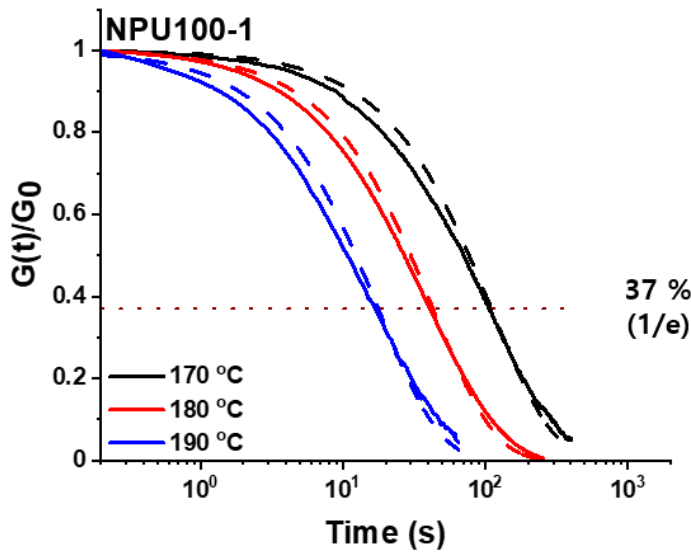

(b)

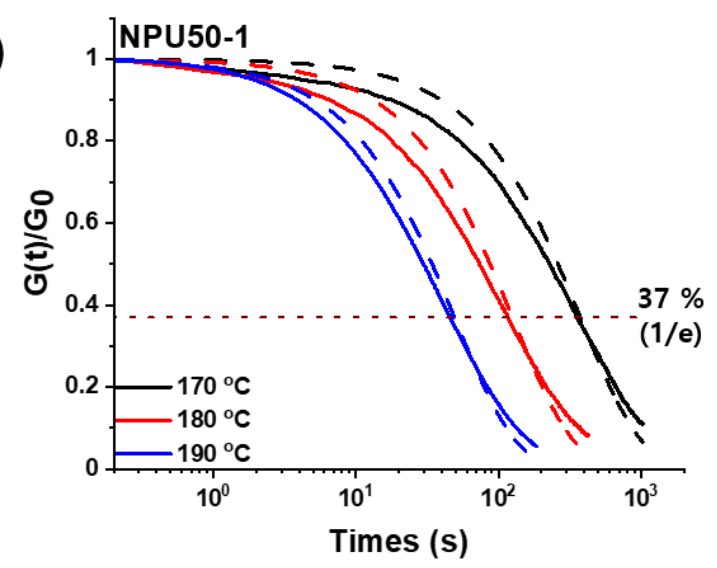

(d)

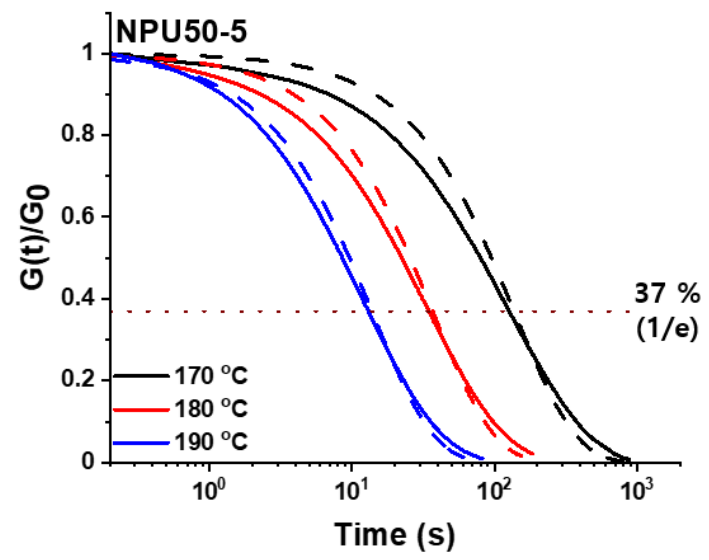

Fig. S10 Isothermal stress-relaxation analysis curves of (a) NPU0-1, (b) NPU50-1, (c) NPU100-1 and (d) NPU50-5. Dotted curves are corrected by the Maxwell equation. 


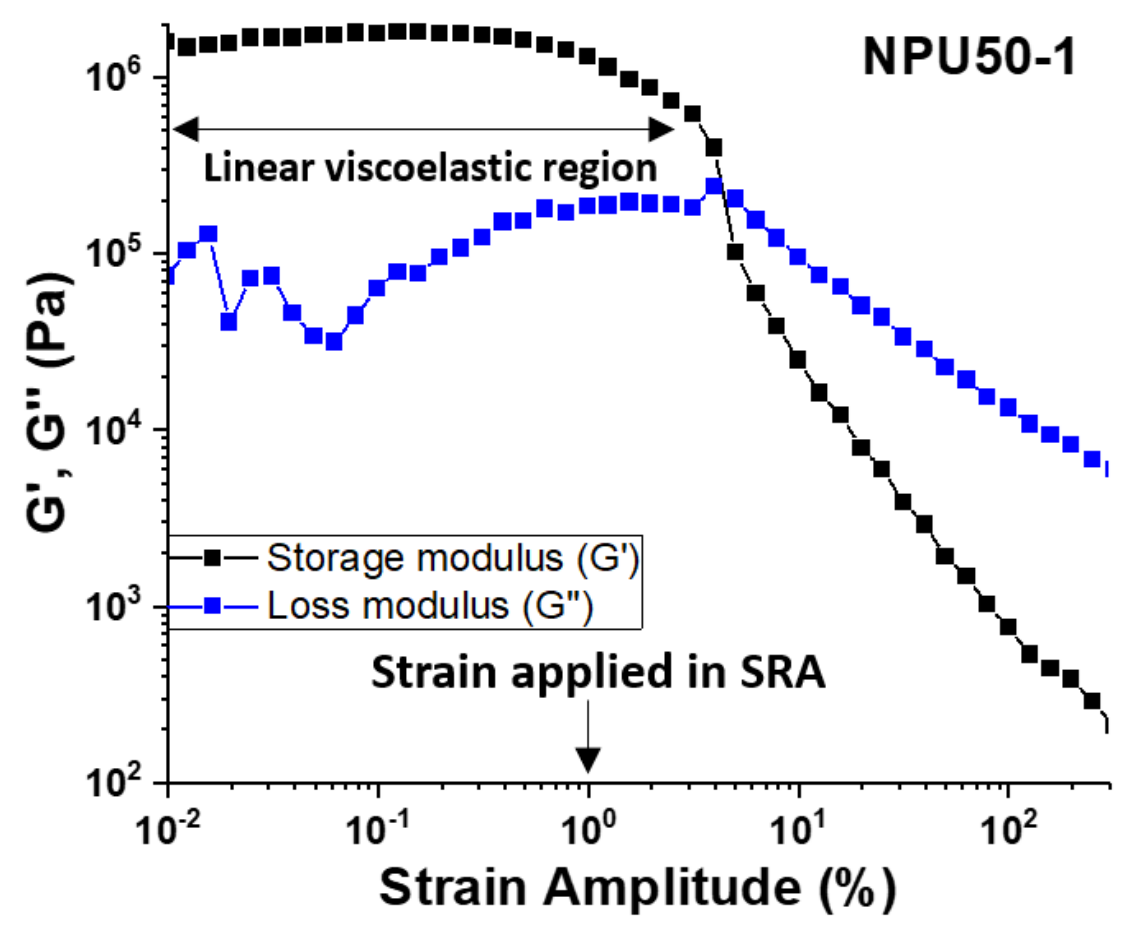

Fig. S11 Storage (G') and loss (G”) moduli in the strain sweep of NPU50-1 at $180{ }^{\circ} \mathrm{C}$. 
Calculations of the theoretical topology freezing transition temperature $\left(T_{v}\right)$ and the activation energy $\left(E_{a}\right)$ in viscosity behaviors of NPUs

In the Maxwell model, ${ }^{1}$ where a linear spring $(E)$ is connected in series with a dashpot $(\eta)$, the stress relaxation under a constant strain can be expressed by equation $\mathrm{S} 1$ or equation $\mathrm{S} 2$, where $\mathrm{E}_{0}$ is its original modulus.

$$
\begin{gathered}
E(t)=E_{0} \times e^{-\frac{E}{\eta} t} \\
\frac{E(t)}{E_{0}}=e^{-\frac{t}{\tau}}
\end{gathered}
$$

The characteristic relaxation time $\left(\tau^{*}\right)$ is a specific time as the modulus $(E(t))$ is decreased to $37 \%(1 / e)$ of its original modulus $\left(E_{0}\right)$. If viscous flow shows Arrhenius-type behavior, it may be described using equation $\mathrm{S} 3$.

$$
\eta=A e^{\frac{E_{a}}{R T}}
$$

where $\mathrm{A}$ is a pre-exponential constant, and $\mathrm{E}_{\mathrm{a}}$ is the activation energy. In addition, the viscosity may be related to the characteristic relaxation time $\left(\tau^{*}\right)$ as equation $\mathrm{S} 1$ and $\mathrm{S} 2$. Thus, if $\ln \left(\tau^{*}\right)$ is plotted against the inverse of the temperature $(T), E_{a}$ can be obtained from the slope values.

In addition, $\mathrm{T}_{\mathrm{v}}$ can be defined as a specific temperature, at which the viscosity is $10^{12} \mathrm{~Pa} \cdot \mathrm{s}$ $\left(\eta^{\prime}\right)$. Using the equations above the characteristic relaxation time $\left(\tau^{*}\right)$ when the specific viscosity $\left(\eta^{\prime}\right)$ is reached could be obtained theoretically., 2 

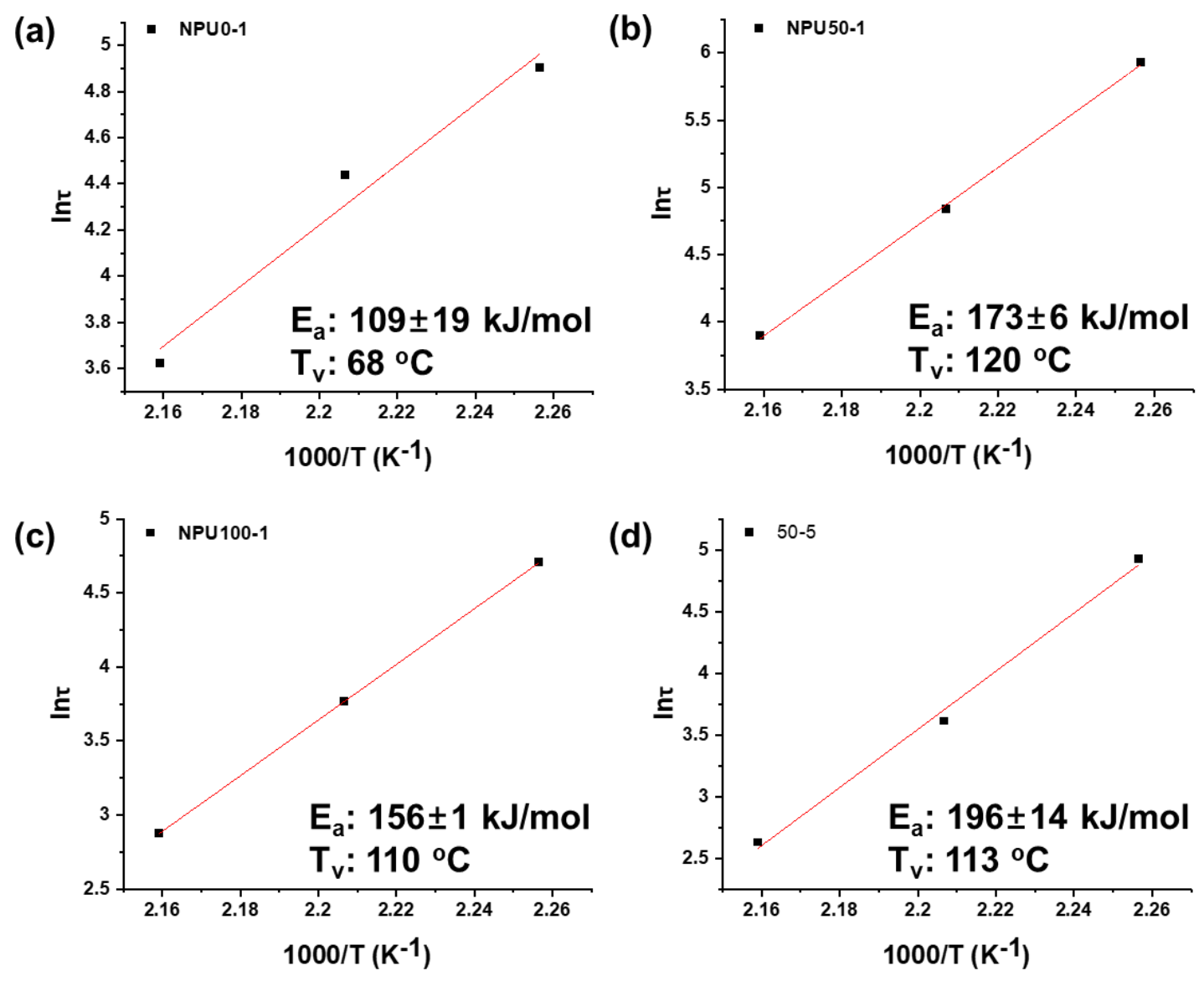

Fig. S12 Arrhenius plots for the viscosity behaviors of (a) NPU0-1, (b) NPU50-1, (c) NPU1001 and (d) NPU50-5 from the characteristic relaxation times in the stress-relaxation analysis. The activation energy and theoretical $\mathrm{T}_{\mathrm{v}}$ of transcarbamoylation of each NPU were determined using these plots. 


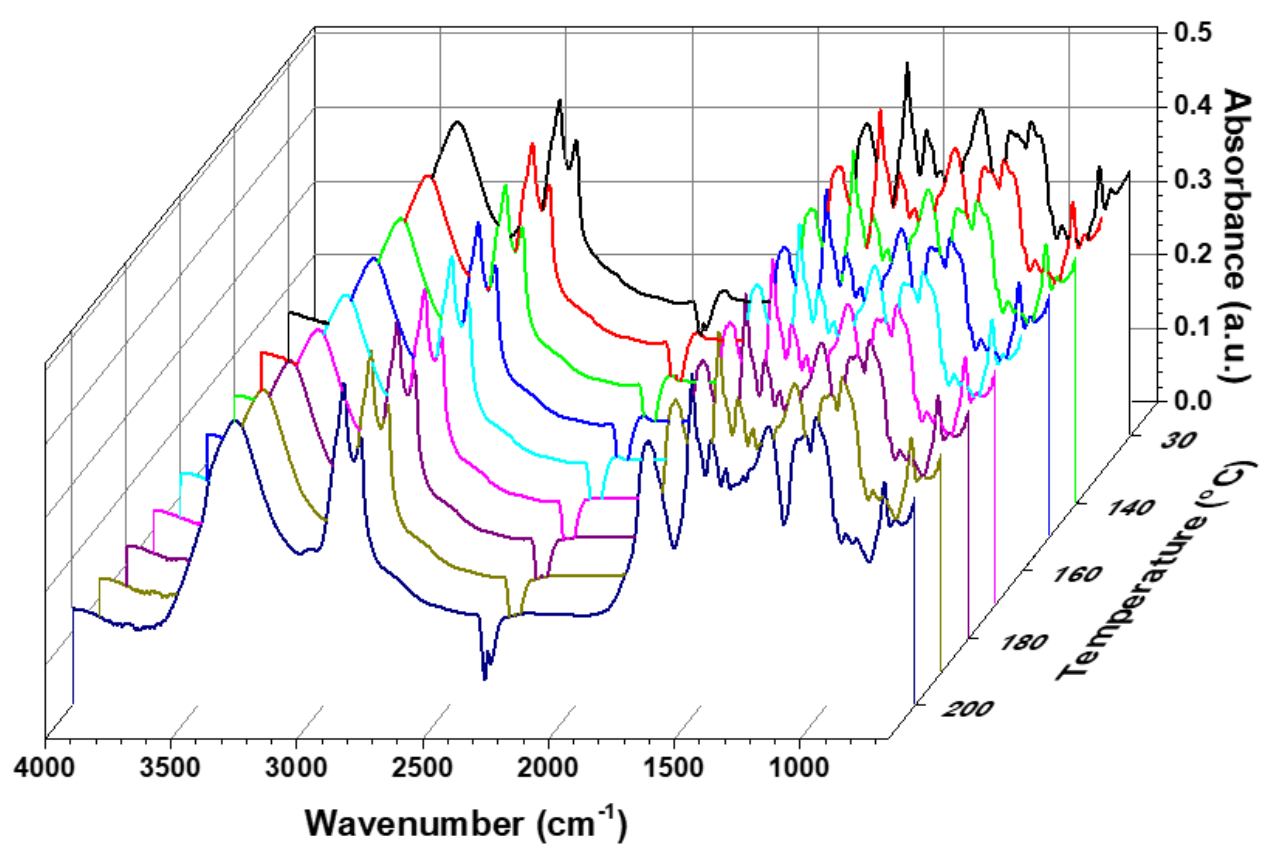

Fig. S13 VT-FTIR spectra of NPU50-1 from $30{ }^{\circ} \mathrm{C}$ to $200{ }^{\circ} \mathrm{C}$. 
(a)

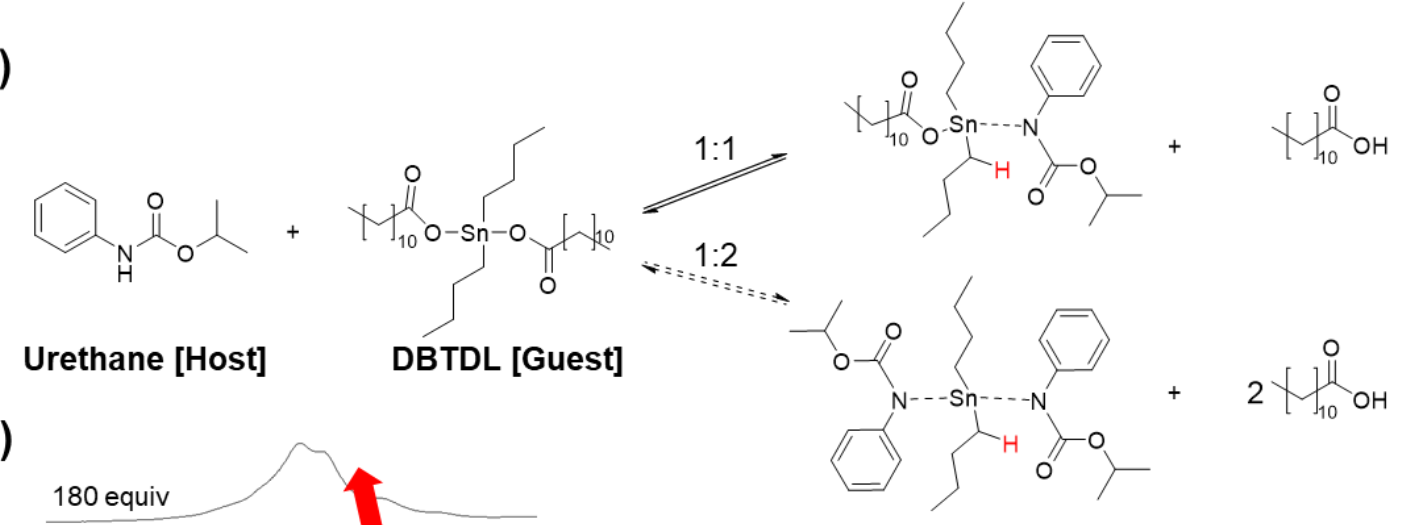

(b)

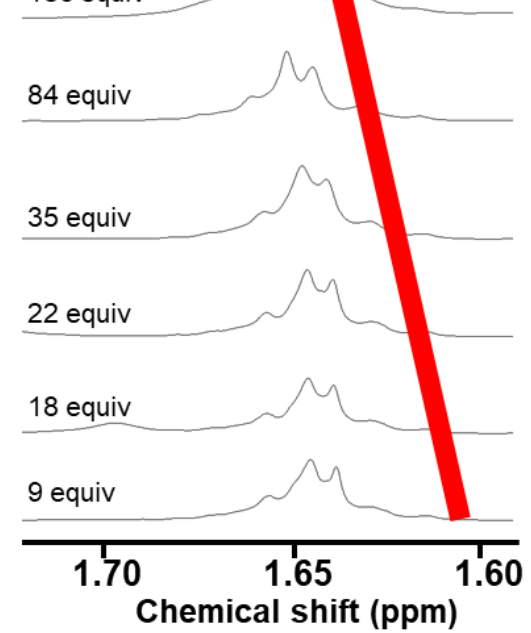

(c)

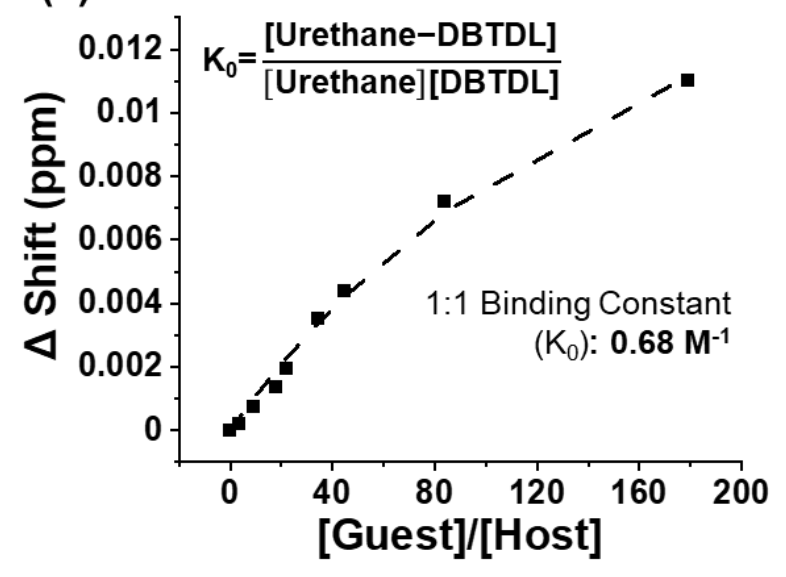

Fig. S14 (a) Schematic representation of urethane and DBTDL complexation through coordinate bond. The 1:1 and 1:2 binding modes were compared. (b) Representative ${ }^{1} \mathrm{H}-\mathrm{NMR}$ titrations of DBTDL using various equivalents of the model urethane compound. (c) Chemical shifts of the nearest butyl protons in DBTDL in ${ }^{1} \mathrm{H}-\mathrm{NMR}$ titrations were plotted against the equivalents of model urethane compound, and its equilibrium constant $\left(\mathrm{K}_{0}\right)$ were evaluated, following literatures ${ }^{4,5}$ and www.supramolecular.org. 


\section{Urethane and Tin catalyst binding test and analysis}

We hypothesized that for the associative transcarbamoylation with the organo tin catalyst (DBTDL), two urethane molecules should be bound to the Sn center at the same time (1:2 binding). Thus, we tested the binding equilibrium between DBTDL (host) and the model urethane compound (guest) from the ${ }^{1} \mathrm{H}-\mathrm{NMR}$ peak shifts that are occurred in the host-guest binding. The near-saturation experiment was then analyzed and the most appropriate binding mode and constant were suggested (Table S1).

Table S1 Calculation of binding constants of 1:1 or 1:2 binding through ${ }^{1} \mathrm{H}-\mathrm{NMR}$ peak shifts using Bindfit (www.supramolecular.org).

\begin{tabular}{ll}
\hline Binding Constant $\left(M^{-1}\right)$ & Error $(\%)$ \\
\hline
\end{tabular}

$1: 1$

$\mathbf{K}_{0}: 0.68$

K11: 8.73

29.8

$1: 2$

K12: 1.38

7.6

As a result, the 1:1 binding model was better-fitted than the 1:2 binding model, suggesting one urethane may bind to the Sn catalyst rather than two urethane moieties. Full details on the equations and terminology used for the binding models used have been published previously.

${ }^{5}$ The most important equations referenced in this paper are summarized below.

$[\mathrm{H}]=$ Concentration of a host molecule (i.e. DBTDL)

$[\mathrm{G}]=$ Concentration of a guest molecule (i.e. Urethane),

\section{1:1 Binding system}

$$
\begin{gathered}
K_{0}=\frac{[H-G]}{[H][G]} \\
{[\mathrm{H}]_{0}=[\mathrm{H}]+[\mathrm{H}-\mathrm{G}]} \\
{[\mathrm{G}]_{0}=[\mathrm{G}]+[\mathrm{H}-\mathrm{G}]}
\end{gathered}
$$




$$
\begin{gathered}
\Delta \operatorname{shift}(\delta)=\delta \Delta\left(\frac{[\mathrm{H}-\mathrm{G}]}{[\mathrm{H}]_{0}}\right) \\
{[\mathrm{G}]=\frac{1}{2}\left(\mathrm{G}_{0}-\mathrm{H}_{0}-\frac{1}{\mathrm{~K}_{0}}\right)-\sqrt{\left(\mathrm{G}_{0}-\mathrm{H}_{0}-\frac{1}{\mathrm{~K}_{0}}\right)^{2}+4 \frac{\mathrm{G}_{0}}{\mathrm{~K}_{0}}}} \\
{[\mathrm{HG}]=\frac{1}{2}\left(\mathrm{G}_{0}+\mathrm{H}_{0}-\frac{1}{\mathrm{~K}_{0}}\right)-\sqrt{\left(\mathrm{G}_{0}+\mathrm{H}_{0}+\frac{1}{\mathrm{~K}_{0}}\right)^{2}+4\left[\mathrm{H}_{0}\right]\left[\mathrm{G}_{0}\right]}}
\end{gathered}
$$

\section{1:2 Binding system}

$$
\begin{gathered}
\mathrm{K}_{11}=\frac{[\mathrm{H}-\mathrm{G}]}{[\mathrm{H}][\mathrm{G}]} \\
\mathrm{K}_{12}=\frac{\left[\mathrm{H}-\mathrm{G}_{2}\right]}{[\mathrm{H}][\mathrm{H}-\mathrm{G}]} \\
{[\mathrm{H}]_{0}=[\mathrm{H}]+[\mathrm{H}-\mathrm{G}]+\left[\mathrm{H}-\mathrm{G}_{2}\right]} \\
{[\mathrm{G}]_{0}=[\mathrm{G}]+[\mathrm{H}-\mathrm{G}]+\left[\mathrm{H}-\mathrm{G}_{2}\right]} \\
\Delta \operatorname{shift}(\delta)=\left(\frac{\delta_{\Delta \mathrm{HG}} \mathrm{K}_{11}[\mathrm{G}]+\delta_{\Delta \mathrm{HG} 2} \mathrm{~K}_{11} \mathrm{~K}_{12}[\mathrm{G}]^{2}}{1+\mathrm{K}_{11}[\mathrm{G}]+\mathrm{K}_{11} \mathrm{~K}_{12}[\mathrm{G}]^{2}}\right)
\end{gathered}
$$




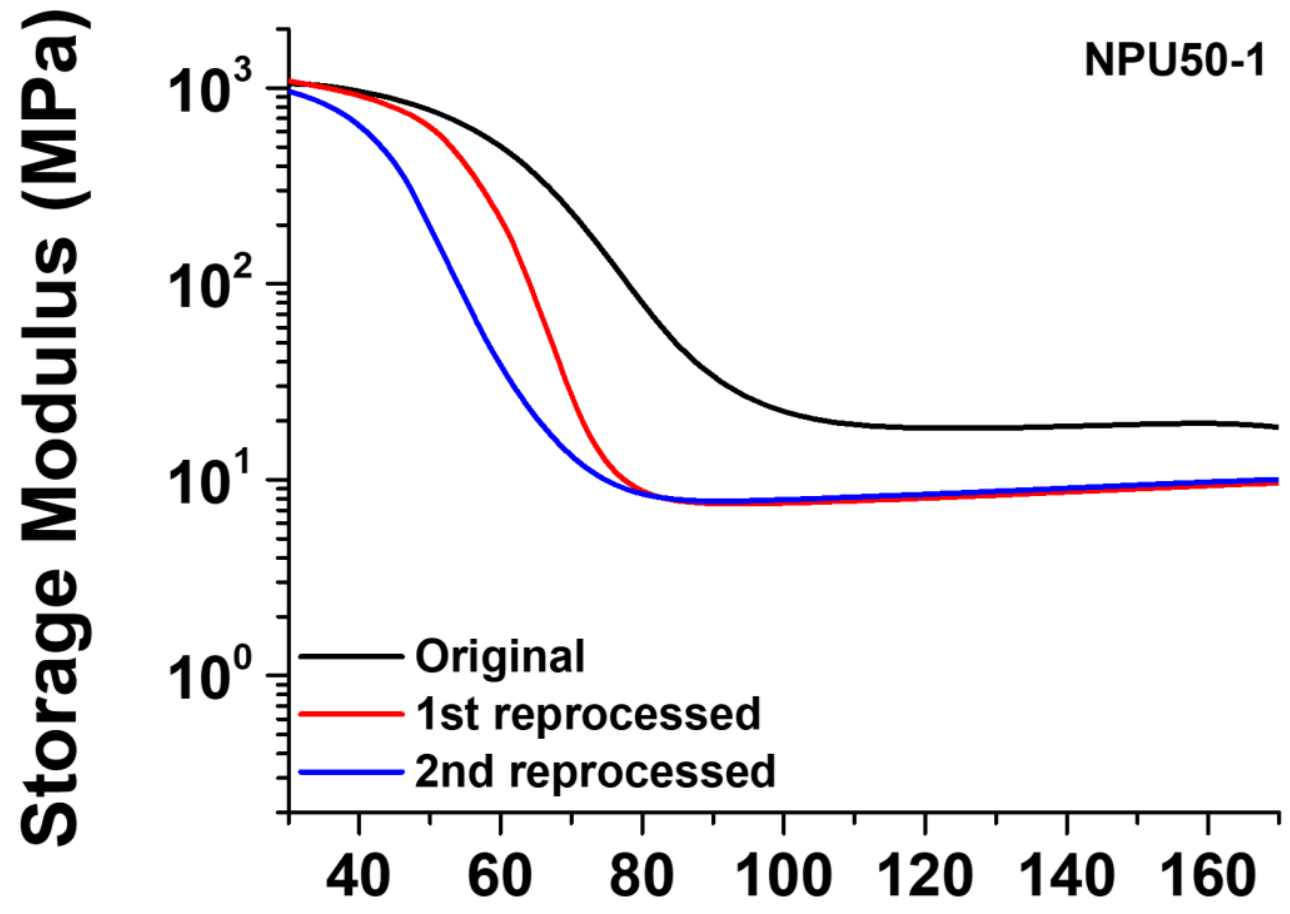

Fig. S15 DMTA curves of the original and reprocessed NPU50-1. 


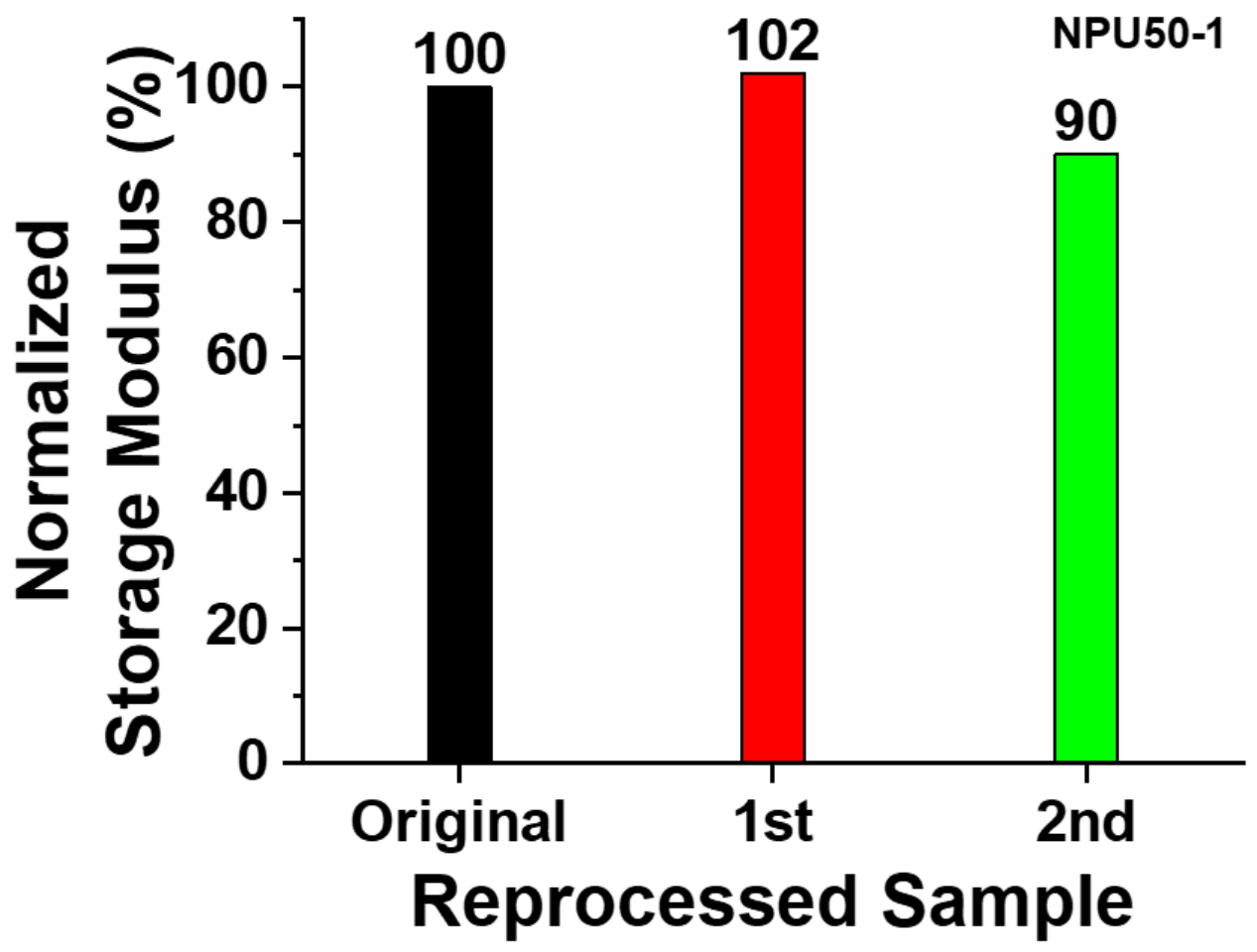

Fig. S16 Normalized storage modulus of the original and reprocessed NPU50-1 at $25^{\circ} \mathrm{C}$. 


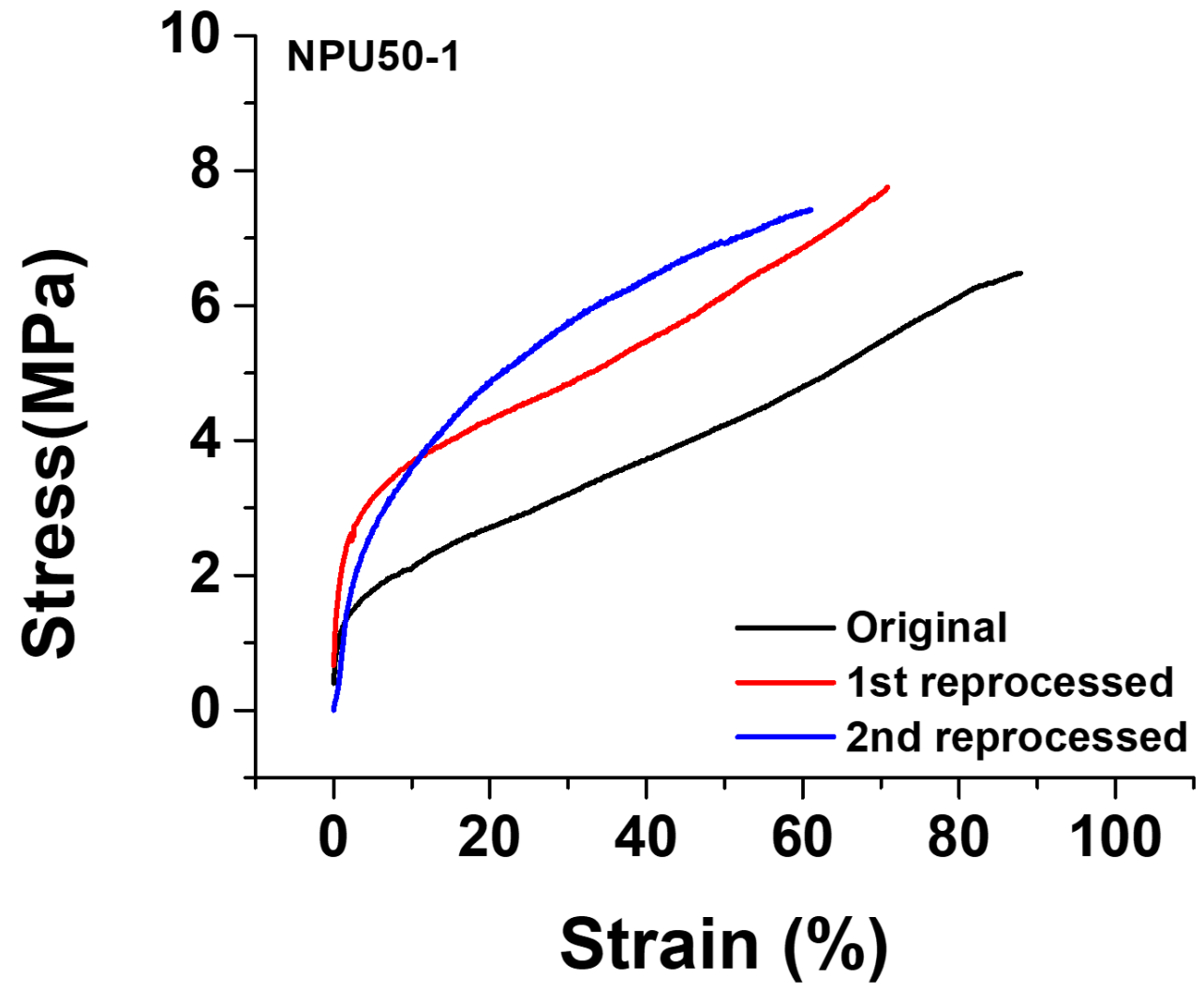

Fig. S17 Strain-stress curves of the original and reprocessed NPU50-1. 


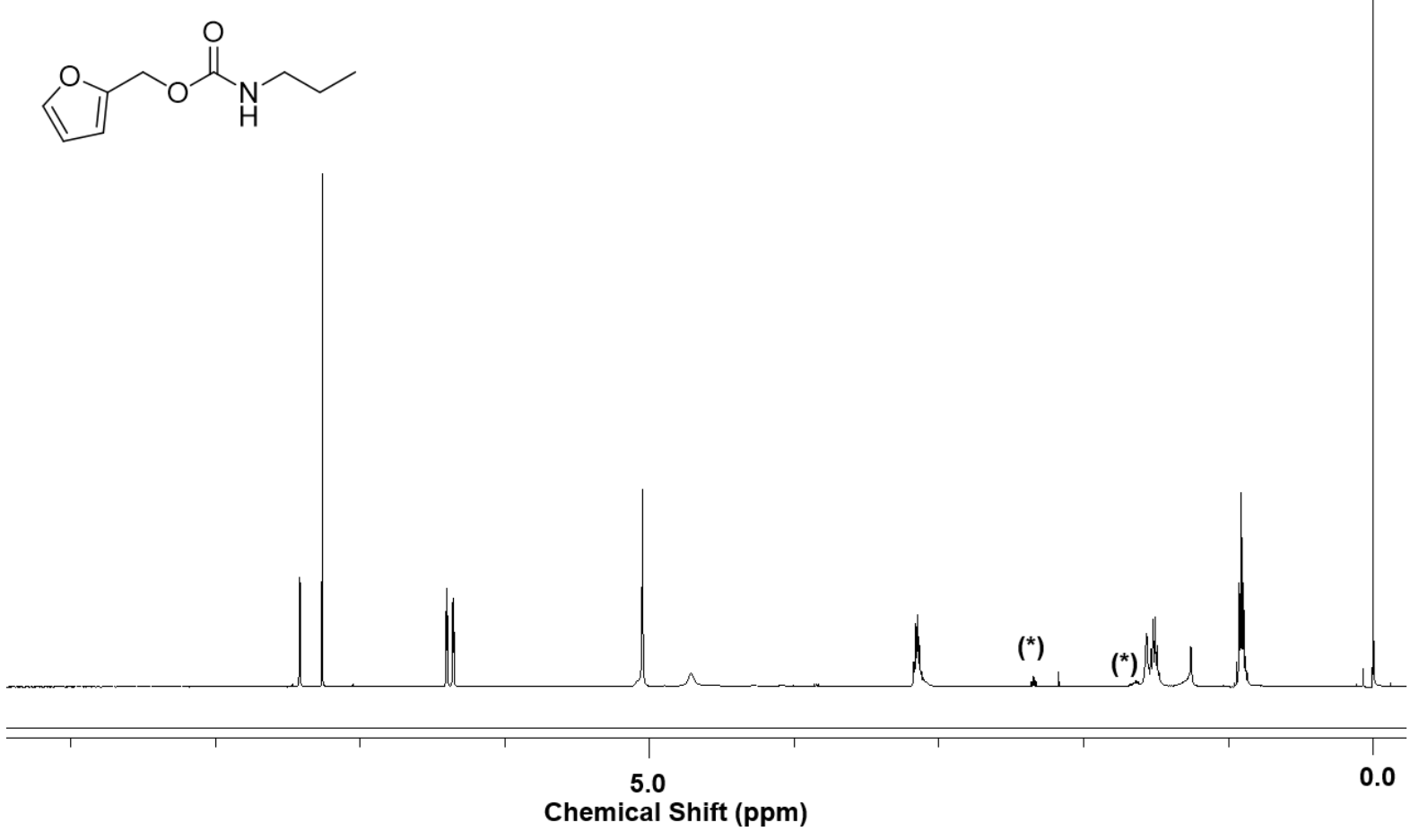

Fig. S18 ${ }^{1} \mathrm{H}$-NMR of fufuryl $N$-propylcarbamate (A).<smiles>CCCCCCNC(=O)OCc1ccco1</smiles>
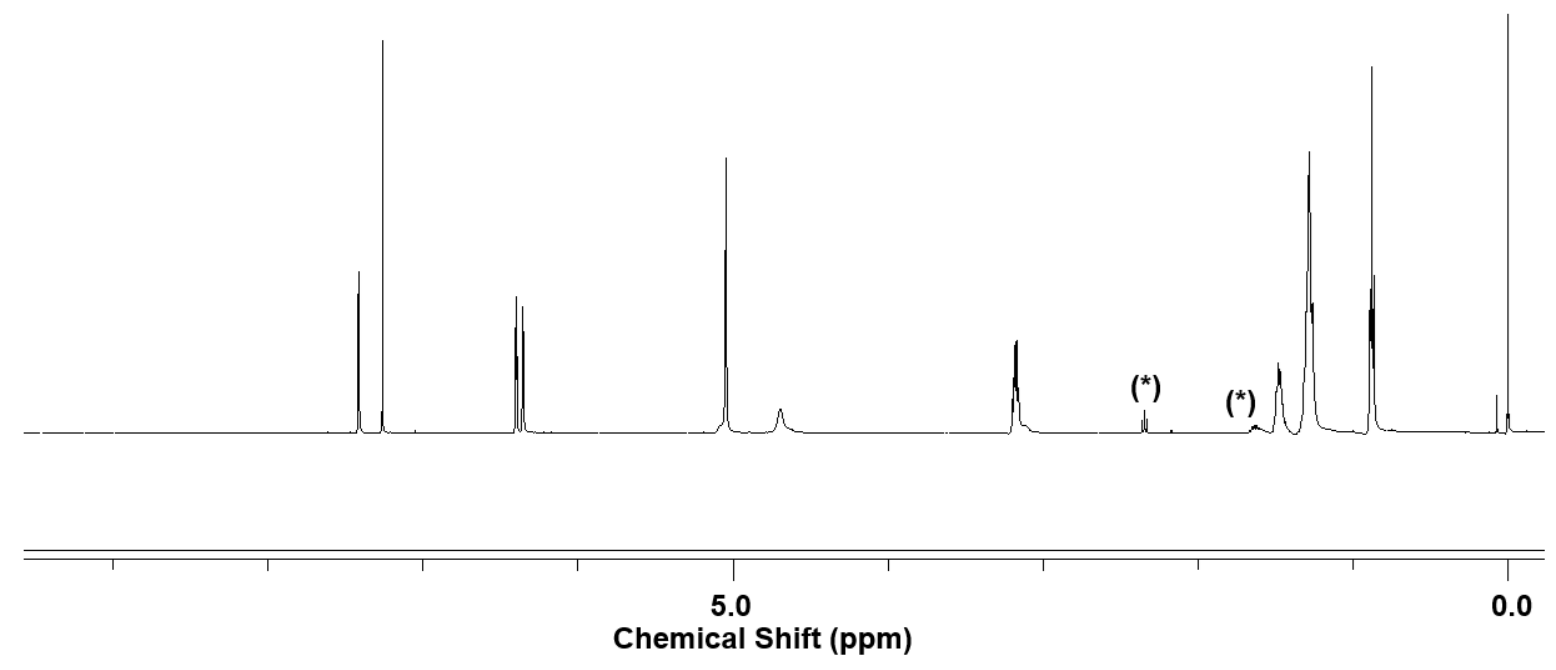

Fig. S19 ${ }^{1} \mathrm{H}$-NMR of fufuryl $N$-hexylcarbamate (C). 


\section{References}

1. Xu, Q.; Engquist, B., A mathematical model for fitting and predicting relaxation modulus and simulating viscoelastic responses. Proc. Math. Phys. Eng. Sci. 2018, 474 (2213), 20170540.

2. Yang, X.; Guo, L.; Xu, X.; Shang, S.; Liu, H., A fully bio-based epoxy vitrimer: Self-healing, triple-shape memory and reprocessing triggered by dynamic covalent bond exchange. Materials \& Design 2020, 186 .

3. Tellers, J.; Pinalli, R.; Soliman, M.; Vachon, J.; Dalcanale, E., Reprocessable vinylogous urethane cross-linked polyethylene via reactive extrusion. Polym. Chem. 2019, 10 (40), 5534-5542.

4. Howe, E. N.; Bhadbhade, M.; Thordarson, P., Cooperativity and complexity in the binding of anions and cations to a tetratopic ion-pair host. J. Am. Chem. Soc. 2014, 136 (20), 7505-7516.

5. Brynn Hibbert, D.; Thordarson, P., The death of the Job plot, transparency, open science and online tools, uncertainty estimation methods and other developments in supramolecular chemistry data analysis. Chem. Commun. 2016, 52 (87), 12792-12805. 